\title{
Clinical and cost-effectiveness of left ventricular assist devices as destination therapy for people with end-stage heart failure: A systematic review and economic evaluation
}

\author{
Andrew J. Clegg \\ University of Southampton \\ David A. Scott \\ Oxford Outcomes Ltd. \\ Emma Loveman, Jill Colquitt \\ University of Southampton \\ Pam Royle \\ University of Aberdeen \\ Jackie Bryant \\ University of Southampton
}

Objectives: The clinical and cost-effectiveness of left ventricular assist devices as destination therapy for people with end-stage heart failure is assessed through a systematic review and economic evaluation.

Methods: Systematic review was performed of randomized controlled trials, quasiexperimental studies, case series, and case studies identified through searching

\footnotetext{
We thank the advisory group for this study for advice and peer review of a draft of the original report for the National Health Service Research and Development Health Technology Assessment (NHS R\&D HTA) Programme: Professor S. Ball, Leeds General Infirmary, Leeds, UK; Professor Martin Buxton, University of Brunel, UK; Ms. Noreen Caine, Papworth Hospital NHS Trust, Cambridge, UK; Professor J. Cleland, University of Hull, Hull, UK; Dr. Mick Davies, University Hospital Birmingham NHS Trust, Birmingham, UK; Mr. Stephen Large, Papworth Hospital NHS Trust, Cambridge, UK; Dr. S. Ludgate, Medicines and Healthcare Products Regulatory Agency, London, UK; Dr. P. McCarthy, Department of Thoracic and Cardiovascular Surgery, The Cleveland Clinic, Cleveland, Ohio; Dr. A. Moskowitz, INCHOIR, Columbia University, New York, New York; Professor John Pepper, Royal Brompton Hospital, London, UK; Mr. L. Vale, Health Economics Research Unit, University of Aberdeen, Aberdeen, UK; Mr. Stephen Westaby, John Radcliffe Hospital, Oxford, UK; Professor Sir M.H. Yacoub, Imperial College London and The Magdi Yacoub Institute NHLI at Heart Science Centre, Harefield, Middlesex, UK. In addition, the following are several people who provided data, translated papers, or assisted in extracting data for this study: J. Fawell, Papworth Hospital NHS Trust, Cambridge, UK; Liz Hodson, University of Southampton, UK; Dr. Christine Clar, Germany; Sian Thomas, Orkney Isles, UK; Mariam Brazzelli, University of Aberdeen, Scotland; Sacci Thomas, Winchester, UK; Dr. Goro Matsumiya, Osaka University Graduate School of Medicine, Japan; Dr. Deereck Wheeldon, WorldHeart, UK; Dr. Charles Glanville, Thoratec Europe, Ltd., Cambridge, UK; Karen Brennan, Thoratec Europe, Ltd., Cambridge, UK; Dr. P. Jansen, Jarvik Heart, Inc., New York, New York; Dr. Janine Meehan, Jarvik Heart, Inc., New York, New York; Dallas Anderson, MicroMed Technology, Inc., Houston, Texas; Yosuke Kobayashi, Toyobo Co., Ltd., Osaka, Japan; Dr. Bill Gutteridge, Medical Adviser, NSCAG, Department of Health, London, UK; Dr. N. Banner, Royal Brompton and Harefield NHS Trust, London, UK. There are no competing interests. This project was funded by the UK Department of Health through its Health Technology Assessment Programme (HTA project reference 01/12/02). The opinions and conclusions expressed here are those of the authors and do not necessarily reflect those of the UK National Health Service or the Department of Health. As the project was funded by the Department of Health, it is covered by Crown Copyright.
} 
eighteen electronic databases, bibliographies, and consultation with experts and manufacturers. Studies assessed survival, functional capacity, and quality of life. Cost-effectiveness was assessed through a 5-year decision analytic model to estimate the incremental cost-effectiveness ratio for using left ventricular assist devices compared with usual care.

Results: Six studies met the inclusion criteria, showing that left ventricular assist devices appear beneficial, improving survival and quality of life. Adverse events are a serious concern. The economic evaluation showed that left ventricular assist devices had a cost per quality adjusted life year of $£ 170,616$. Sensitivity analysis showed that the cost-effectiveness was not sensitive to changes in costs or utility.

Conclusions: Although left ventricular assist devices appear clinically effective as destination therapy, it is unlikely they will be cost-effective unless costs decrease or the benefits of their use increase.

Keywords: Heart failure, Left ventricular assist devices, Systematic review, Economic evaluation, Health technology assessment

For people with severe or end-stage heart failure (ESHF), treatment options are limited. Heart transplantation has been the only treatment that has provided substantial benefit, improving the length and quality of life $(3 ; 18)$. Serious shortages in donor organs have restricted the use of heart transplantation to a few $(11 ; 12 ; 19)$. As a result, increasing attention has focused on the role of mechanical circulatory support, either as a replacement for the natural heart (total artificial hearts) or as a support that works in parallel with the heart (ventricular assist device). Left ventricular assist devices (LVADs), originally developed to bridge people to heart transplantation, have continued to evolve. Miniaturization, low power use, and ease of implantation, allied with decreasing costs and advances in patient care, have made LVADs an acceptable treatment option (14). With the increasing scarcity of donor organs for transplantation, people have been supported for longer periods, extending to months or even years. Inevitably, this finding has raised the possibility of using LVADs as destination therapy, providing an alternative through long-term chronic support for those awaiting heart transplantation or those ineligible for transplantation. With the fast changing nature of the technology and more than twenty different devices having been developed, uncertainty remains as to the suitability of these devices as destination therapy. Before adopting new technologies, it is important to evaluate the evidence of their benefits, risks, and costs. This study summarizes the results of a systematic review and economic evaluation commissioned by the Department of Health's Health Technology Assessment Programme to assess the evidence of the clinical and cost-effectiveness of all available LVADs used as destination therapy for people with ESHF (2).

\section{METHODS}

We searched for published and unpublished studies using eighteen electronic databases, including Medline, Cochrane Library, and Embase, from their inception to December 2004 with no language restrictions (details of search strategy available elsewhere) (2). Also, we searched through bibliographies of related publications and contacted relevant experts and manufacturers of LVADs to identify additional references. Studies reported as abstracts or conference presentations were only considered for inclusion if adequate details of their methodology and results were provided to judge the quality and rigor of the study.

We included randomized controlled trials (RCTs), controlled clinical trials, cohort studies, case series, and case studies that evaluated currently available LVADs used as destination therapy for people 16 years of age and older with ESHF. Natural history studies were sought as it was recognized that experimental studies of this rapidly evolving technology may be scarce. These studies may provide useful evidence of effectiveness where outcomes are poor and predictable without treatment (21). We placed an emphasis on including studies that used the most rigorous study designs and that included an appropriate comparator, whether another LVAD or optimal medical management. We excluded studies if LVADs were used during the perioperative period only or as an emergency rescue strategy during an operation. Studies were included if they assessed survival, functional capacity, or quality of life as primary outcome measures. Standard criteria were used to assess the quality of included studies $(1 ; 20)$. Two reviewers independently applied inclusion criteria, extracted data, and assessed quality. Any differences were resolved through independent assessment by a third reviewer. We extracted standard information on study characteristics, methods, and results wherever possible to allow comparison across different studies. Clinical effectiveness was assessed through a narrative comparison of different outcomes. Differences in, or insufficient details on, study designs, outcomes used, patient characteristics, or intervention used precluded meta-analysis.

The economic evaluation developed for this study was a cost utility analysis using a decision analytic model based on a Markov approach. A detailed discussion of the 
methodology used to develop the evaluation is available elsewhere (2). It compared the benefits and costs of the use of LVADs with that of usual medical care as destination therapy for people with ESHF through calculation of an incremental cost-effectiveness ratio (ICER) (6). The evaluation adopted an National Health Service and Personal Social Services perspective for costs and benefits for 2003 (UK prices). The base case focused on devices that were considered to be the most clinically effective in the systematic review. Benefits were assessed in terms of changes in patient survival and quality of life. The Randomized Evaluation of Mechanical Assistance for the Treatment of Congestive Heart Failure (REMATCH) study (15), which compared the HeartMate Vented Electric (VE) LVAD with optimal medical management, provided the only source of data measuring patient survival with an indication of time to an event through Kaplan-Meier survival curves. Although these survival curves were censored at 30 months, we extended these through survival analysis until all patients had died (60 months) to ensure all survival benefits were accounted for in the model. No studies reporting utility values for destination therapy were identified by the systematic review. Instead, we obtained utility values using a panel-based approach, mapping the Minnesota Living with Heart Failure questionnaire to utilities using different scenarios from data reported in the REMATCH study $(2 ; 15)$. Costs reflected current clinical practice in the United Kingdom and originate from the systematic review, expert clinical advice, UK hospitals, and device manufacturers (Table 1) (2). Benefits were discounted at 1.5 percent and costs at 6 percent. Results were presented as incremental cost per quality-adjusted

Table 1. Component Costs Used in the Economic Evaluation

\begin{tabular}{|c|c|c|c|}
\hline Component & 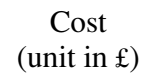 & $\begin{array}{l}\text { Event rate } \\
\text { per patient }\end{array}$ & $\begin{array}{c}\text { Total cost } \\
\text { per patient }(\mathfrak{f})\end{array}$ \\
\hline \multicolumn{4}{|l|}{ LVAD costs } \\
\hline $\begin{array}{l}\text { Pre-LVAD implant } \\
\text { assessments }^{\mathrm{a}}\end{array}$ & 2,202 & 1.3125 & 2,891 \\
\hline Implant operation $^{\mathrm{a}}$ & 36,986 & 1 & 36,986 \\
\hline $\begin{array}{l}\text { Follow-up outpatient } \\
\text { visit }^{\mathrm{a}}\end{array}$ & 99 & 6 & 595 \\
\hline Readmissions $^{\mathrm{a}}$ & 5,391 & 3 & 16,174 \\
\hline $\begin{array}{l}\text { Total charge excluding } \\
\text { device }\end{array}$ & & & 56,645 \\
\hline $\begin{array}{l}\text { HeartMate/Novacor } \\
\text { devices }^{\mathrm{b}}\end{array}$ & & & 48,000 \\
\hline $\begin{array}{l}\text { MicroMed DeBakey } \\
\text { device }^{\mathrm{b}}\end{array}$ & & & 35,000 \\
\hline Jarvik device $^{\mathrm{c}}$ & & & $40,948^{\mathrm{d}}$ \\
\hline $\begin{array}{l}\text { LVAD ongoing } \\
\text { management costs }\end{array}$ & Quarterly & & 4,192 \\
\hline Medical management $\mathrm{t}^{\mathrm{a}}$ & Quarterly & & 1,382 \\
\hline
\end{tabular}

life-years (QALYs) gained (6). One-way and multiway sensitivity analyses examining different devices, costs, utilities, efficacy, and discounting were carried out.

\section{RESULTS}

\section{Systematic Review of Clinical Effectiveness}

Six studies assessing the clinical effectiveness of LVADs as destination therapy for ESHF met the inclusion criteria, with studies of the HeartMate VE LVAD (15), LionHeart LVAD (7), Novacor LVAD (4;5), Toyobo LVAD (16), and Jarvik 2000 LVAD $(8 ; 10 ; 17 ; 22 ; 24)$. Only the RCT assessing the HeartMate VE LVAD included a comparator (15), that of optimal medical management, with the remaining studies being either case studies $(4 ; 5 ; 7 ; 9 ; 16)$ or case series $(8 ; 10 ; 17 ; 22 ; 24)$.

\section{Quantity and Quality of Evidence}

The methodological quality and the quality of reporting of the case series and case studies were judged to be weak. The five studies lacked rigorous study designs and allocation process, as well as providing limited information on the selection of participants, blinding, and methods of data collection (Table 2) $(4 ; 5 ; 7 ; 10 ; 16 ; 17 ; 22 ; 24)$. In contrast, the RCT comparing the use of the HeartMate VE LVAD with optimal medical management was judged to be moderate in its methodological quality and quality of reporting (15). Although it had a strong study design and appeared to use appropriate methods of allocation, it lacked an adequate description of the actual methods of randomization. The RCT was judged to be weak in its selection of a representative patient group, a consequence of changes to the a priori selection criteria to ensure adequate enrollment. The risk of confounding was considered low as the study demonstrated that there were no significant differences between groups. Blinding of patients and treating surgeons to interventions was impossible and, despite efforts to limit the effects of observational bias through the use of independent blinded observers to judge outcomes, was judged to be methodologically weak. The validity and reliability of data collection tools was considered weak due to the limited discussion in the trial report. Reporting of withdrawals and drop-outs was thought to be methodologically strong, identifying numbers of, and reasons for, withdrawal as well as undertaking an intention to treat analysis. The external validity of the studies was assessed through a comparison of the characteristics of the different patient groups (2). Although limited information was provided, studies tend to focus on male patients 60 years of age and older who had suffered ischemic or dilated cardiomyopathy and were ineligible for heart transplantation.

\section{Survival}

Studies showed that people supported with an LVAD had a survival benefit when compared with those on optimal 
Clegg et al.

Table 2. Methodological Quality and Quality of Reporting of Studies

\begin{tabular}{|c|c|c|c|c|c|c|c|c|}
\hline Study & $\begin{array}{l}\text { Study design } \\
\& \text { comparator }\end{array}$ & $\begin{array}{l}\text { Design \& } \\
\text { allocation }\end{array}$ & Selection & Confounding & Blinding & $\begin{array}{l}\text { Data } \\
\text { collection }\end{array}$ & Withdrawals & $\begin{array}{l}\text { Intention } \\
\text { to treat }\end{array}$ \\
\hline \multicolumn{9}{|l|}{ HeartMate LVAD } \\
\hline Rose et al. (15) & $\begin{array}{l}\text { RCT } \\
\quad \text { (Optimal medical } \\
\text { management) }\end{array}$ & Moderate & Weak & Strong & Weak & Weak & Strong & Yes \\
\hline \multicolumn{9}{|l|}{ LionHeart LVAD } \\
\hline $\begin{array}{c}\text { El Banayosy } \\
\text { et al. (7) }\end{array}$ & $\begin{array}{l}\text { Case reports } \\
\text { (No comparator) }\end{array}$ & Weak & Weak & $\begin{array}{l}\text { Not } \\
\quad \text { applicable }\end{array}$ & Weak & Weak & $\begin{array}{l}\text { Not } \\
\quad \text { applicable }\end{array}$ & $\begin{array}{l}\text { Not } \\
\quad \text { applicable }\end{array}$ \\
\hline \multicolumn{9}{|l|}{ Novacor LVAD } \\
\hline $\begin{array}{l}\text { Dohmen } \\
\quad \text { et al. }(4 ; 5)\end{array}$ & $\begin{array}{l}\text { Case report } \\
\text { (No comparator) }\end{array}$ & Weak & Weak & $\begin{array}{l}\text { Not } \\
\quad \text { applicable }\end{array}$ & Weak & Weak & $\begin{array}{l}\text { Not } \\
\quad \text { applicable }\end{array}$ & $\begin{array}{l}\text { Not } \\
\quad \text { applicable }\end{array}$ \\
\hline \multicolumn{9}{|l|}{ Toyobo LVAD } \\
\hline Seki et al. (16) & $\begin{array}{l}\text { Case report } \\
\quad \text { (No comparator) }\end{array}$ & Weak & Weak & $\begin{array}{l}\text { Not } \\
\quad \text { applicable }\end{array}$ & Weak & Weak & $\begin{array}{l}\text { Not } \\
\quad \text { applicable }\end{array}$ & $\begin{array}{l}\text { Not } \\
\quad \text { applicable }\end{array}$ \\
\hline \multicolumn{9}{|l|}{ Jarvik 2000 LVAD } \\
\hline Frazier et al. (9) & $\begin{array}{l}\text { Case report } \\
\text { (No comparator) }\end{array}$ & Weak & Weak & $\begin{array}{l}\text { Not } \\
\quad \text { applicable }\end{array}$ & Weak & Weak & $\begin{array}{l}\text { Not } \\
\quad \text { applicable }\end{array}$ & $\begin{array}{l}\text { Not } \\
\quad \text { applicable }\end{array}$ \\
\hline Frazier et al. (10) & $\begin{array}{l}\text { Case series } \\
\quad \text { (No comparator) }\end{array}$ & Weak & Weak & $\begin{array}{l}\text { Not } \\
\quad \text { applicable }\end{array}$ & Weak & Weak & $\begin{array}{l}\text { Not } \\
\quad \text { applicable }\end{array}$ & $\begin{array}{l}\text { Not } \\
\quad \text { applicable }\end{array}$ \\
\hline
\end{tabular}

Note. The different criteria were rated following the guidelines provided by Thomas and colleagues (20), with some adaptations. Where criteria are rated as weak, moderate, or strong, it relates to the study's methodological control of the criteria. As such, if a study is rated as strong, it indicates that there is a low risk of bias for the particular criteria. Where a component is considered not to be relevant to a study design, it is referred to as not applicable. LVAD, left ventricular assist device; RCT, randomized controlled trial.

medical management or to the natural history of ESHF (Table 3). The REMATCH trial reported that the HeartMate VE LVAD provided a statistically significant 48 percent reduction in the risk of death from any cause at 30 months compared with optimal medical management (15). Actuarial survival was significantly higher for people with the HeartMate VE LVAD compared with optimal medical management at 1 year (survival difference 27 percent) and 2 years (survival difference 15 percent) follow-up. Survival benefits from the HeartMate LVAD were evident for people 60 years of age and younger and those 60 to 69 years of age at 1-year follow-up. Studies of other devices were limited to case studies or case series with no comparator, providing only an indication of any additional benefit gained when compared with the natural history of the ESHF. A series of six case studies of the LionHeart LVAD showed all survived implantation of the device and that 50 percent survived to 18 months postimplantation (7). Case studies of the Novacor and Toyobo LVADs reported that a patient receiving a Novacor LVAD survived for over 4 years before dying $(4 ; 5)$ and a patient receiving a Toyobo LVAD was still alive after 6 months (16). A case series of seven patients who received a Jarvik 2000 LVAD reported that five continued to undergo support $(8 ; 10 ; 17 ; 22 ; 24)$. Mean survival for the four patients at the UK center was 502 days (range, 95 to 889 days) and for the 3 patients at the German center was 93 days (range, 66 days to 145 days). A separate case report of the Jarvik 2000 LVAD reported survival of a patient until discharge 6 weeks after implantation (9).

\section{Functional Status}

Changes to functional status were assessed in the REMATCH trial and a case series $(15 ; 23)$. The REMATCH trial showed that significantly more patients surviving on the HeartMate LVAD experienced improvement in their functional status on the New York Heart Association (NYHA) functional classification (baseline 100 percent NYHA IV; 12 months 100 percent NYHA II) compared with those on optimal medical management (baseline 100 percent NYHA IV; 12 months 64 percent NYHA IV) (15). Similar improvements on NYHA functional classification were reported in a case series for three patients with Jarvik 2000 LVAD (baseline 100 percent NYHA IV; 4 weeks postimplantation 66 percent NYHA I, 33 percent NYHA II) (23).

\section{Quality of Life}

The REMATCH trial and a case series of the Jarvik 2000 LVAD provided the only evidence on changes in quality of life following LVAD implantation (Table 4) (15;23). Patients with the HeartMate LVAD reported a significantly better quality of life at 12 months after device implantation on the physical function and emotional role subscales of the thirty-six item Medical Outcomes Study Short-Form General Health Survey and on the Beck Depression Inventory when compared with patients on optimal medical management (15). Similar improvements were shown on the Minnesota Living with Heart Failure questionnaire, although differences were not statistically significant. A case series of 
Table 3. Summary of Evidence of the Effect of LVADs on Patient Survival

\begin{tabular}{|c|c|c|c|c|}
\hline Study & Outcomes & LVAD & Comparison & $p$ value \\
\hline \multicolumn{5}{|l|}{ HeartMate LVAD } \\
\hline \multirow[t]{6}{*}{ Rose et al. (15) } & Survival at 1 year (actuarial) & $52 \%$ & $25 \%$ & $=.002$ \\
\hline & Survival at 2 years (actuarial) & $23 \%$ & $8 \%$ & $=.09$ \\
\hline & Median survival & 408 days & 150 days & \\
\hline & $\begin{array}{l}\text { Death from any cause } \\
\text { (Kaplan-Meier analysis over } \\
30 \text { months) }\end{array}$ & $\mathrm{RR}, .52 ; 95 \% \mathrm{CI}, .34-.78 ; p=.001$ & & \\
\hline & $\begin{array}{l}\text { 1-year survival in patients } \\
60 \text { years old and younger }\end{array}$ & $74 \%(n=13)$ & $33 \%(n=9)$ & $=.05$ \\
\hline & $\begin{array}{l}\text { 1-year survival inpatients } 60 \text { to } \\
69 \text { years old }\end{array}$ & $47 \%(n=29)$ & $15 \%(n=20)$ & $=.009$ \\
\hline \multicolumn{5}{|l|}{ LionHeart LVAD } \\
\hline \multirow[t]{2}{*}{ El Banayosy et al. (7) } & Operative mortality & $\begin{array}{l}100 \% \text { survived implantation } \\
\quad(n=6)\end{array}$ & No comparator & Not applicable \\
\hline & $\begin{array}{l}\text { Survival at } 18 \text { months } \\
\text { postimplantation }\end{array}$ & $\begin{array}{l}50 \% \text { survived }(n=6) .3 \text { patients } \\
\text { died at } 17,31 \text {, and } 112 \text { days }\end{array}$ & No comparator & Not applicable \\
\hline \multicolumn{5}{|l|}{ Novacor LVAD } \\
\hline Dohmen et al. $(4 ; 5)$ & Survival & $\begin{array}{l}\text { Patient survived } 1,514 \text { days and } \\
\text { died of causes unrelated to the } \\
\text { pump }\end{array}$ & No comparator & Not applicable \\
\hline \multicolumn{5}{|l|}{ Toyobo LVAD } \\
\hline Seki et al. (16) & Survival & $\begin{array}{l}\text { Patient died } 190 \text { days after } \\
\text { surgery }\end{array}$ & No comparator & Not applicable \\
\hline \multicolumn{5}{|l|}{ Jarvik 2000 LVAD } \\
\hline Frazier et al. (9) & Survival postimplantation & $\begin{array}{l}\text { Patient survived for } 6 \text { weeks until } \\
\text { discharged }\end{array}$ & No comparator & Not applicable \\
\hline $\begin{array}{l}\text { Westaby et al. (23) and } \\
\text { Frazier et al. (10) }\end{array}$ & Survival & $\begin{array}{l}\text { UK study }(n=4): 3 \text { patients left } \\
\text { hospital within } 4 \text { weeks (one } \\
\text { report states that } 3 \text { patients left } \\
\text { hospital within } 3-8 \text { weeks), } 2 \\
\text { patients died at } 95 \text { days and } \\
382 \text { days; the surviving } 2 \\
\text { patients were still supported } \\
\text { after } 642 \text { and } 889 \text { days. } \\
\text { German study }(n=3): 3 \\
\text { patients surviving at follow-up }\end{array}$ & No comparator & Not applicable \\
\hline
\end{tabular}

LVAD, left ventricular assist device; RR, relative risk; CI, confidence interval.

Table 4. Summary of Evidence of Quality of Life of Patients

\begin{tabular}{|c|c|c|c|}
\hline Outcomes & Intervention & Comparison & $p$ value \\
\hline \multicolumn{4}{|l|}{ Rose et al. (15) } \\
\hline \multicolumn{4}{|c|}{ Quality of life/function at 12 months } \\
\hline \multirow[t]{2}{*}{ Physical function } & No. assessed: 23/24 (96\%) & No. assessed: 6/11 (55\%) & $=.01$ \\
\hline & Score: 46 (SD 19) & Score: $21(\mathrm{SD} 21)$ & \\
\hline \multirow[t]{2}{*}{ Emotional role } & No. assessed: 23/24 (96\%) & No. assessed: 6/11 (55\%) & $=.03$ \\
\hline & Score: 64 (SD 45) & Score: 17 (SD 28) & \\
\hline \multirow{2}{*}{$\begin{array}{l}\text { Minnesota Living with } \\
\text { Heart Failure score }\end{array}$} & No. assessed: 23/24 (96\%) & No. assessed: 6/11 (55\%) & $=.11$ \\
\hline & Score: 41 (SD 22) & Score: 58 (SD 21) & \\
\hline \multirow[t]{2}{*}{ Beck Depression Inventory } & No. assessed: 22/24 (92\%) & No. assessed: 5/11 (45\%) & $=.04$ \\
\hline & Score: 8 (SD 7) & Score: 13 (SD 7) & \\
\hline \multicolumn{4}{|l|}{ Westaby et al. (23) } \\
\hline \multirow{7}{*}{$\begin{array}{c}\text { Minnesota Living with } \\
\text { Heart Failure score }\end{array}$} & UK study $(n=4)$ & Not applicable & Not applicable \\
\hline & Patient 1: Pre-LVAD 89, Post-LVAD 24 & & \\
\hline & Patient 2: Pre-LVAD 76, Post-LVAD died & & \\
\hline & Patient 3: Pre-LVAD 83, Post-LVAD 38 & & \\
\hline & Patient 4: Pre-LVAD 87, Post-LVAD 45 & & \\
\hline & German study $(n=3)$ & Not applicable & Not applicable \\
\hline & $\begin{array}{l}\text { Pre-LVAD 75.2 (SD 11.4), Postimplant } \\
\quad(2 \text { months) } 30.0 \text { (SD 18.6) }\end{array}$ & & \\
\hline
\end{tabular}

LVAD, left ventricular assist device. 
seven patients with the Jarvik 2000 LVAD showed that quality of life of the surviving patients improved following implantation of the device (23).

\section{Adverse Events}

Serious adverse events were common among people with ESHF who received either an LVAD or optimal medical therapy. People receiving a HeartMate LVAD were twice as likely to suffer a serious adverse event as those on optimal medical management (rate ratio [RR], 2.35; 95 percent confidence interval $[\mathrm{CI}], 1.86-2.95)$, with significantly higher rates of non-neurological bleeding (RR, 9.47; 95 percent CI, 2.30$38.90)$ and neurologic dysfunction (RR, 4.35; 95 percent CI, 1.31-14.50) (15). Also those with a HeartMate LVAD had higher rates of supraventricular arrhythmias (RR, 3.92; 95 percent CI, .47-32.40), sepsis (RR, 2.03; 95 percent CI, .994.13), local infection (RR, 1.63; 95 percent CI, .72-3.70), renal failure (RR, 1.42; 95 percent $\mathrm{CI}, .54-3.71)$, miscellaneous adverse events (RR, 1.41; 95 percent CI, .93-2.12), syncope (RR, 1.31; 95 percent CI, .12-14.40), and serious psychiatric disease (RR, 1.31; 95 percent $C I, .12-14.30)$ than patients receiving optimal medical management. In contrast, people receiving optimal medical management had higher rates of ventricular arrhythmias (RR, .45 ; 95 percent $\mathrm{CI}, .22$ .90), cardiac arrest (RR, .65; 95 percent CI, .21-2.00), and nonperioperative myocardial infarction (RR, .65 ; 95 percent CI, .04-10.30). Of the patients who died while supported by a HeartMate LVAD, 41 percent were due to sepsis, 17 percent to LVAD failure, and 10 percent to cerebrovascular disease. Some 93 percent of the deaths among optimal medical management patients were due to left ventricular dysfunction. A series of six case reports of the LionHeart LVAD showed that patients suffered from temporary hemolysis (50 percent), bleeding (50 percent), early arrhythmia (40 percent), and other adverse events (7). It was reported that none of the patients with the LionHeart LVAD were readmitted with infection, thromboembolic complications, or arrhythmias. Case studies of the Novacor $(4 ; 5)$ and Toyobo (16) LVADs reported that a patient with the Novacor device suffered from transient renal failure, bronchopneumonia, and febrile episodes due to device-related infection, whereas a patient with a Toyobo LVAD suffered from multiple cerebral embolisms and thrombi within the pump. The case series of seven patients with Jarvik 2000 LVADs reported a case of dyspnea, ventricular tachycardia, power supply problems, and infection $(8 ; 10 ; 17 ; 22 ; 24)$. No other device-related malfunctions or infections were reported.

\section{Cost-Effectiveness of LVADs as Destination Therapy for ESHF}

With no relevant cost-effectiveness studies available (2), we developed an economic evaluation to assess the costeffectiveness of LVADs as destination therapy within the UK setting. A base case comparison of the use of the HeartMate LVAD with optimal medical management showed that the LVAD offered an additional .6 quality-adjusted life-years (QALYs) per patient over the 5-year duration of the model at an additional cost of $£ 102,000$, producing an incremental cost per QALY of £170,616 (Table 5).

One-way sensitivity analysis has shown that the model was not sensitive to changes in costs, discount rates, or changes in utility (Table 5). Only when survival improves by 60 percent and device costs are reduced by 60 percent compared with the base case scenario does the incremental cost-effectiveness ratio approach the generally accepted cost-effectiveness thresholds for the United Kingdom (cost per QALY, £30,000) (13).

\section{DISCUSSION}

The systematic review has revealed the lack of good quality evidence assessing the clinical effectiveness of LVADs as destination therapy for people with ESHF. Despite these limitations, it appears that LVADs are beneficial when compared with optimal medical management or to the natural history of ESHF, improving the length and quality of life of patients. However, it is evident that adverse events were associated with their use, including device malfunctions, infections, and bleeding. When comparing the various devices, the evidence was less clear due to the scarcity and poor quality of the studies available, as well as the lack of direct comparisons. Only the REMATCH trial comparing the HeartMate VE LVAD with optimal medical management had sufficient rigor to judge efficacy, showing benefit for patients with an LVAD on measures of survival, functional status, and quality of life. Studies of the Novacor, LionHeart, Toyobo, and Jarvik 2000 were of poor methodological quality with no comparator, limiting any comparison. Further investigations are needed to adequately compare the different devices, taking into account the developments in devices, implantation techniques, and patient care.

Limited evidence on the cost-effectiveness of LVADs as destination therapy necessitated the development of a de novo economic evaluation for the United Kingdom (2). The analysis showed that LVADs are not a cost-effective option with a cost per QALY of $£ 170,616$, which lies outside the threshold for acceptability in the United Kingdom of $£ 30,000$ per QALY (13). One-way sensitivity analysis showed that cost-effectiveness was not sensitive to changes in the costs associated with care, discount rates, or measures of utility. In fact, multiway sensitivity analysis showed that there would need to be reductions of over 60 percent in the cost of the devices as well as substantial improvements of over 60 percent in the length and quality of life of the patient for costeffectiveness to reach a cost per QALY of $£ 30,000$. Although it is likely that the cost of devices will decline as the technology develops and diffuses, doubts remain as to the extent to which additional benefits can be achieved. Some of the uncertainty reflects limitations in the evidence on benefits and costs available, particularly for the new axial flow devices. 
Table 5. Baseline Results and Sensitivity Analyses

Baseline results

\begin{tabular}{lccc}
\hline & LVAD & Optimal medical management & Increment \\
\hline Costs per patient per 3 months & & & 1,382 \\
Initial 3 months (£) & 87,877 & 1,382 & 86,495 \\
Each subsequent 3 months (6-63 months) (£) & 4,192 & .70 & 2,811 \\
Utility per patient & .93 & .23 \\
Cohort (100 patients) & & 562,991 & $10,470,141$ \\
Total cost, undiscounted (£) & $11,033,131$ & 50.07 & 64.53 \\
Total QALYs, undiscounted & 114.60 & 475,807 & $10,199,835$ \\
Total cost, discounted (£) & $10,675,641$ & 44.41 & 59.78 \\
Total QALYs, discounted & 104.19 & & $£ 170,616$ \\
Incremental cost-effectiveness ratio & & & \\
\hline
\end{tabular}

One-way and multiway sensitivity analyses

\begin{tabular}{|c|c|c|c|c|c|}
\hline \multirow{2}{*}{$\begin{array}{l}\text { Parameter varied } \\
\text { Baseline }\end{array}$} & \multirow{2}{*}{$\frac{\text { Base case }}{-}$} & \multicolumn{2}{|c|}{ Range of values tested } & \multicolumn{2}{|c|}{ Cost per QALY $(£)$ (range) } \\
\hline & & - & - & \multicolumn{2}{|c|}{170,616} \\
\hline Upper and lower estimates of costs & - & $-20 \%$ & $+20 \%$ & 136,597 & 190,283 \\
\hline LVAD operation cost $(£)$ & 36,986 & 29,589 & 44,383 & 158,242 & 182,989 \\
\hline LVAD management cost $(£)$ & 16,769 & 13,415 & 20,123 & 164,300 & 176,932 \\
\hline Medical management cost $(£)$ & 5,526 & 4,421 & 16,769 & 154,423 & 172,207 \\
\hline 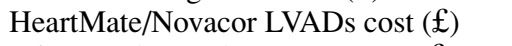 & 48,000 & 38,400 & 57,600 & 154,557 & 186,674 \\
\hline MicroMed DeBakey LVAD cost (£) & 48,000 & 28,000 & 42,000 & 137,161 & 160,579 \\
\hline Jarvik 2000 LVAD cost $(£)$ & 48,000 & 32,758 & 49,137 & 145,120 & 172,518 \\
\hline \multicolumn{5}{|l|}{ Improvement over REMATCH survival/ } & 61,154 \\
\hline MicroMed DeBakey VAD device cost & Not applicable & $+60 \% /-60 \%$ & $+40 \% /-40 \%$ & 44,339 & 54,692 \\
\hline Costs discount rate & $6 \%$ & $3 \%$ & $9 \%$ & 169,638 & 171,656 \\
\hline Benefits discount rate & $1.5 \%$ & $0 \%$ & $6 \%$ & 167,059 & 181,491 \\
\hline \multicolumn{6}{|l|}{ Mean expert-based utilities } \\
\hline - Baseline (pretrial) & .55 & & & & \\
\hline - On LVAD support & .925 & & & 178,426 & \\
\hline • On drug therapy & .7 & & & & \\
\hline
\end{tabular}

LVAD, Left ventricular assist device; QALY, quality-adjusted life-years; REMATCH, Randomized Evaluation of Mechanical Assistance for the Treatment of Congestive Heart Failure.

Consistent methods for undertaking systematic reviews and economic evaluations were applied, with support throughout the process from an expert advisory group of clinicians, academics, and health professionals from the United States and United Kingdom. Contact was made with manufacturers, the major specialist centers implanting LVADs in the United Kingdom, and authors of studies to try and obtain additional information, with varying success. The economic evaluation used the most up to date data available, with evidence from our systematic review of clinical effectiveness, patient utility data from on-going primary research using a panel-based approach, and cost data from specialist centers in the United Kingdom and device manufacturers.

Although the evaluation included different types of devices, the evidence on benefits and costs tended to focus on the more established displacement pulsatile devices, particularly the HeartMate LVAD. With the emergence of the new axial flow devices and their increasing use in clinical practice, it is inevitable that the evidence base will continue to improve. It will be important to incorporate any emerging evidence into our systematic review and economic evaluation to ensure it accurately assesses their benefits, risks, and costs.

Several areas for research have emerged, including the epidemiology of ESHF to assess incidence, prevalence, and characteristics of sufferers; long-term (at least 5 years followup) RCTs focusing on head to head comparisons of different devices and optimal medical management that encompass a broad range of patient groups and assess patient survival, functional ability, quality of life, and adverse events; and economic evaluations as part of clinical trials with prospective collection of data on quality of life, utilities, resources, and costs.

\section{POLICY IMPLICATIONS}

New developments in LVADs and the management of patients have brought optimism concerning the permanent use of LVADs for people with ESHF. The lack of alternative treatment options has increased attention on the possibility 
of developing a specialist service within the United Kingdom. Despite the limited evidence assessing the effectiveness of LVADs as destination therapy, our study has shown that LVADs appear to be clinically effective, improving survival and quality of life. However, currently they are not a costeffective option. As a consequence, it is unlikely that funding of a service within the UK National Health Service would be justified at present. Despite this outlook, it will be important to continue to fund further good quality comparative research to assess the benefits, risks, and costs of this rapidly developing technology. This research should be undertaken as part of a nationally coordinated and funded formal research program allowing the research objectives to be progressed while maintaining the skills and structure of the current service.

\section{CONTACT INFORMATION}

Andrew J. Clegg, PhD (a.clegg@soton.ac.uk), Professor and Director, Southampton Health Technology Assessments Centre, Wessex Institute for Health Research and Development, Mailpoint 728, University of Southampton, Southampton SO16 7PX. UK

David A. Scott, MA (david.scott@oxfordoutcomes.com), Principal Health Economist, Oxford Outcomes Ltd., Seacourt Tower, West Way, Oxford, OX2 0JJ, UK

Emma Loveman, PhD (e.loveman@soton.ac.uk), Senior Research Fellow, Jill Colquitt, PhD (j.colquitt@soton. ac.uk), Senior Research Fellow, Southampton Health Technology Assessments Centre, Wessex Institute for Health Research and Development, Mailpoint 728, University of Southampton, Southampton, SO16 7PX, UK

Pam Royle, PhD (p.royle@abdn.ac.uk), Senior Research Fellow, Department of Public Health, University of Aberdeen, Medical School Buildings, Foresterhill, Aberdeen AB25 2ZD, UK

Jackie Bryant, MSc (J.S.Bryant@soton.ac.uk), Senior Research Fellow, Southampton Health Technology Assessments Centre, Wessex Institute for Health Research and Development, Mailpoint 728, University of Southampton, Southampton, SO16 7PX, UK

\section{REFERENCES}

1. Centre for Reviews and Dissemination. Undertaking systematic reviews of research on effectiveness. No. 4. York: CRD; 2001.

2. Clegg AJ, Scott DA, Loveman E, et al. The clinical and cost effectiveness of left ventricular assist devices for end stage heart failure: A systematic review and economic evaluation. Health Technol Assess. 2005;9:1-148.

3. Deng MC. Orthotopic heart transplantation: Highlights and limitations. Surg Clin North Am. 2004;84:243-255.

4. Dohmen PM, Laube H, de Jonge K, et al. Mechanical circulatory support for one thousand days or more with the Novacor N100 left ventricular assist device. J Thorac Cardiovasc Surg. 1999;117:1029-1030.

5. Dohmen PM, Laube H, de Jonge K, Konertz W. A reliable test to detect impending pump failure during long-term support on the NovacorR N100 Left Ventricular Assist System. Tex Heart Inst J. 2001;28:139-141.

6. Drummond MF, Sculpher MJ, Torrance GW, O'Brien BJ, Stoddart GL. Methods for the economic evaluation of health care programmes. Oxford: Oxford University Press; 2005.

7. El Banayosy A, Arusoglu L, Kizner L, et al. Preliminary experience with the LionHeart left ventricular assist device in patients with end-stage heart failure. Ann Thorac Surg. 2003;75:14691475.

8. Frazier OH, Myers TJ, Gregoric ID, et al. Initial clinical experience with the Jarvick 2000 implantable axial-flow left ventricular assist system. Circulation. 2002;105:2855-2860.

9. Frazier OH, Myers TJ, Jarvik RK, et al. Research and development of an implantable, axial-flow left ventricular assist device: The Jarvik 2000 Heart. Ann Thorac Surg. 2001;71:S125-S132.

10. Frazier $\mathrm{OH}$, Myers TJ, Westaby S, Gregoric ID. Use of the Jarvik 2000 left ventricular assist system as a bridge to heart transplantation or as destination therapy for patients with chronic heart failure. Ann Surg. 2003;237:631-637.

11. Hogness JR, VanAntwerp M. The artificial heart: Prototypes, policies and patients. Washington DC: National Academy Press; 1991.

12. Kherani AR, Oz MC. Ventricular assistance to bridge to transplantation. Surg Clin North Am. 2004;84:75-89.

13. Miner AH, Garau M, Fidan D, Fischer AJ. Comparing estimates of cost effectiveness submitted to the National Institute for Clinical Excellence (NICE) by different organisations: Retrospective study. BMJ. 2005;330:65-68.

14. Park SJ, Tector A, Piccione W, et al. Left ventricular assist devices as destination therapy: A new look at survival. J Thorac Cardiovasc Surg. 2005;129:9-17.

15. Rose EA, Gelijns AC, Moskowitz AJ, et al. Long-term mechanical left ventricular assistance for end-stage heart failure. N Engl J Med. 2001;345:1435-1443.

16. Seki T, Kitamura S, Kawachi K, et al. Efficacy and limitation of a left ventricular assist system in a patient with dilated cardiomyopathy accompanying multi-organ dysfunction. J Cardiovasc Surg (Torino). 1995;36:147-151.

17. Siegenthaler MP, Martin J, van de Loo A, et al. Implantation of the permanent Jarvick 2000 left ventricular assist device. J Am Coll Cardiol. 2002;39:1764-1772.

18. Souhami RL, Moxham J. Textbook of medicine. London: Churchill Livingstone; 1994.

19. Taggart DP, Westaby S. Surgical management of heart failure. BMJ. 1997;314:453-454.

20. Thomas BH, Ciliska D, Dobbins M, Micucci S. A process for systematically reviewing the literature: Providing the research evidence for public health nursing interventions. Worldviews Evid Based Nurs. 2004;1:176-184.

21. Waugh NR. Grading of scientific evidence. Health Bull. 1999;57:53-63.

22. Westaby S, Banning AP, Saito S, et al. Circulatory support for long-term treatment of heart failure: Experience with an intraventricular continuous flow pump. Circulation. 2002;105:25882591.

23. Westaby S, Frazier OH, Beyersdorf F, et al. The Jarvick 2000 heart. Clinical validation of the intraventricular position. Eur J Cardiothorac Surg. 2002;22:228-232.

24. Westaby S, Jarvik R, Freeland A, et al. Postauricular percutaneous power delivery for permanent mechanical circulatory support. J Thorac Cardiovasc Surg. 2002;123:977-983. 